\title{
An autoethnographic narrative of the diasporic experience of a Chinese female Ph.D. returnee's entry into the domestic academic job market during COVID-19: An ecological environment perspective
}

\author{
Yanru $X \mathbf{u}^{1}$ (D) \\ Received: 3 June 2021 / Revised: 4 November 2021 / Accepted: 7 November 2021 / Published online: 23 November 2021 \\ (c) Education Research Institute, Seoul National University, Seoul, Korea 2021
}

\begin{abstract}
In this study, Chinese female Ph.D. returnees' diasporic experience when entering into the domestic academic job market (DAJM) was examined from an ecological environment perspective. This was realized through an autoethnographic narrative of the author's lived experience of entering the DAJM during the COVID-19 pandemic. Through a recollection of the narrative recorded through E-diaries, emails, and visual media, specifically WeChat, from April 2020 to May 2021, the findings revealed that such a diasporic experience comprised diasporic emotion because of expectational pressures in the microsystem, diasporic identity conflict that originated from gender stereotypes in the mesosystem, self-reflexive diasporic consciousness of both disadvantages and advantages related to Guanxi (social networks) in the exosystem, the diasporic feeling of being exiled in the DAJM given the academic culture in relation to degree origin bias and prioritizing publications in the macrosystem, and the self-constructed diasporic mindset that experienced uncertainties and anxieties associated with the COVID-19 pandemic in the chronosystem. This study facilitated a sociological exposition and understanding of the complex situation of Ph.D. returnees' experience of entering the DAJM. It calls for a shifting of blaming the victims risk in relation to hard indicators regarding Ph.D. returnees' competitiveness and employability in the DAJM. This has implications for both academic and recruiting practices in China. Furthermore, this study offers future overseas doctoral students and Ph.D. returnees a more practical sense of the potential mobility frictions embedded in transnational education mobility in relation to their job-seeking experience in homelands.
\end{abstract}

Keywords Ph.D. returnees · Domestic academic job markets · Diaspora $\cdot$ Environment ecology perspective $\cdot$ China

\section{Introduction}

This study contributes to an understanding of Chinese female Ph.D. returnees' diasporic experience when entering the domestic academic job market (DAJM). In this study, the notion of diaspora moves from the traditional understanding of a "location outside a homeland" (Grossman, 2019, p. 2) to "a variety of experience, a state of mind, a sense of identity" (Vertovec, 1997, p. 281). This was realized through an autoethnographic narrative of my lived experience of entering the DAJM by employing the ecological environment perspective (Bronfenbrenner, 1977, 1979, 1986a, b).

Yanru Xu

xuyanru@ucas.ac.cn

1 School of Public Policy and Management, University of Chinese Academy of Sciences, Beijing, China
Studies have revealed the changing job markets in China in relation to recruiting international graduates (Hao et al., 2016), including recruiting Ph.D. returnees in academia (Shen \& Wang, 2018). Since the late 1980s, there has been a rapid and sustained increase of Chinese students who pursue doctoral degrees in global north countries, mainly in the United States, United Kingdom, and Australia (UIS. UNESCO, 2021; Xu et al., 2020). On the contrary, China has experienced a severe trend of the brain drain, especially during the 1990s (Zweig, 2006). Thus, the Chinese government has initiated successive policies to attract overseas degree holders to return to China (Yang \& Marini, 2019). Studies have shown how these returnees have been attracted by pull factors in China (Hu, 2021), including preferential governmental policies (Zweig et al., 2004), career opportunities, and economic prospects (Kellogg, 2012), family ties, and national cultural identity and patriotism (Tharenou \& Seet, 2014). Since the 2000s, the return rate has increased 
significantly. For example, among 662.1 thousand Chinese overseas students in 2018, 78.45\% returned to China. Compared to that of 2000, this was a 55 fold increase (Ministry of Education, 2019).

In order to build world-class universities, China has endeavored to attract global talents by offering considerable incentives for international publications ( $\mathrm{Xu}$ et al., 2021). Studies have revealed that Ph.D. returnees have contributed positively to the effects of the Chinese higher education (HE) on the global stage, including publications in English journals (Li \& Xue, 2020) as well as transnational research collaborations (Jiang \& Shen, 2019). China has also expanded its domestic doctoral education on a large scale. In 2019, there were 424.182 thousand registered doctoral students in Chinese universities (China Statistical Yearbook, 2020). Given the increased return rate of Ph.D. returnees and the domestic expansion of doctoral education, there has been ardent competition for academic positions in the country (Gu et al., 2018). This trend is similar to other national contexts in which an increasing number of Ph.D. graduates accept postdoctoral offers because of the difficulties associated with finding faculty positions directly after their graduation (Conti \& Visentin, 2015; Powell, 2015). Until 2019, approximately 233 thousand Chinese Ph.D. graduates held postdoctoral positions (Ministry of Human Resources \& Social Security, 2019).

Research throughout the world has revealed that both advantages and challenges are experienced during Ph.D. returnees' entry into the DAJM. In comparison to their domestic counterparts, Ph.D. graduates are regarded as national treasures (Chen, 2005), enjoy higher academic status (Jung, 2018; Rizvi, 2000), and are more likely to be promoted to leadership roles (Chen, 2017). Such advantages are accumulated through overseas learning and life experience in relation to transnational human capital such as knowledge and ability (Gerhards et al., 2017), transnational cultural capital, for example, overseas degrees (Kim, 2016), and transnational social capital, including international social networks (Woolley et al., 2008). Some studies have found various factors pose challenges to $\mathrm{Ph}$.D. returnees' employability in the DAJM, including previous publication records (Headworth \& Freese, 2016), institutional prestige (Burris, 2004; Jiang et al., 2020), social networks and inbreeding (Lee \& Kim, 2010), and gender (Silander et al., 2021). As noted, studies have highlighted the complex situations Ph.D. returnees encounter during their entry into the DAJM when exhibiting their competitiveness and employability.

However, in this study, it is argued that there has been a tendency to focus on hard indicators of Ph.D. returnees' competitiveness and employability in the DAJM, including the number of their publications, their institution's ranking, and the quantity and quality of their academic networks. It is risky to blame the victims by ignoring how various external factors in the environment ecology may influence Ph.D. returnees' entry into the DAJM in which they may experience various challenges that are out of their control. Li and Xue (2021) employed the term academic ecology to explore Chinese returnee faculties' interactions with their academic environment in which the focus was on institutional and cultural factors. Although the marginalized status of returnee faculties has been described as "abandoned orphans" inside their local academic ecology (Li \& Xue, 2021, p. 1063), little is known about how external environmental factors influenced their entry into such an academic ecology.

Studies have revealed Chinese Ph.D. returnees encounter challenges in their entry into the DAJM, which is embedded in Chinese academic culture and social norms. For example, publication productivity has been a crucial recruitment criterion in Chinese academia (Yang \& You, 2018) in which the research culture of publish or perish is emphasized ( $\mathrm{Li}$ $\&$ Xue, 2020). To be awarded a Ph.D., it is imperative that the candidate have publications, at least in Chinese journals. It is noteworthy that this is not a requirement in countries such as the United States, United Kingdom, and Australia. Consequently, the academic curriculum vitae (CV) of Ph.D. returnees may not be as competitive as those of their domestic counterparts. Furthermore, guanxi (social networks) have played significant roles in the Chinese job market (Bian, 1994), where the problem of deep-rootedness in Chinese academic job markets has been widely discussed (Jiang et al., 2020). However, to some extent, overseas learning and life experience have caused Chinese Ph.D. returnees to be disconnected from domestic academic networks (Liu, 2019) in that they have limited understanding of the current government policies and local knowledge (Hao \& Welch, 2012). In addition, males with Ph.D. degrees are more likely to be employed in Chinese universities than their female counterparts even though females have exhibited a greater preference to work in academia (Huang \& Shen, 2019; Shen et al., 2018). Thus, certain factors in the external environment that are embedded in academic culture and social norms potentially give Chinese Ph.D. returnees the status of disapora at home, as "stranger[s]-within" (Charusheela, 2007, p. 295) the DAJM.

One would expect such a diasporic status to be intensified during the COVID-19 pandemic because the latter has had an adverse effect on the global job market, causing the worldwide unemployment rate to soar (DDG/P Office \& OECD, 2020). Globally, universities have revoked job searches. Face-to-face interviews have been stopped, thus causing many candidates in academic job markets a high level of uncertainty and anxiety (European University Institute, accessed in April, 2021; Gould, 2020). One may question how Ph.D. returnees experienced their entry into the DAJM during the COVID-19 pandemic. 
Accordingly, in this study, an autoethnographic narrative of my lived experience of entering into the DAJM during COVID-19, as a Chinese female Ph.D. returnee from the UK, was conducted. My diasporic experience, including diasporic emotion, diasporic identity conflict, self-reflexive diasporic consciousness, the diasporic feeling of being exiled, and self-constructed diasporic mindset, which were influenced by various factors in the five layers of the environment ecology perspective, are subsequently presented (Bronfenbrenner, 1977, 1979, 1986a, b). Accordingly, the following research question was answered:

How did a Chinese female Ph.D. returnee enter the DAJM during the COVID-19 pandemic?

\section{Theoretical framework: diasporic experience in the environment ecology}

Traditionally, the notion of diaspora has functioned as a theoretical tool with three main elements since the late 1980s in studies on migration and mobility, namely, "dispersion in space," "orientation to a homeland," and "boundary- maintenance" (Brubaker, 2005, p. 5). In this sense, cross-border movements and displacement seem to be the "defining component" of diaspora (Campt \& Thomas, 2008, p. 2). Gradually, diaspora studies extended to include the dimension of consciousness so as to explore diasporic experience, identity, and mindset (Vertovec, 1997). More recently, increased discussions have focused on diaspora at home: the emotional condition and diasporic experience of being an outsider, including feelings of alienation, isolation, and otherness, in one's homeland (Band, 1996; Kwak \& Song, 2015).

Relevant studies in the Chinese context include the exclusion and frictions experienced by Taiwanese migrants during integration into their ethnic homeland of mainland China (Lin, 2011) as well as Hong Kong students' experiences in relation to their engagement with their mainland peers and higher education institutions (Xu, 2019). As noted previously, Chinese Ph.D. returnees tend to disconnect with domestic academic networks and culture (Liu, 2019) and possess limited understanding of local cultural values and academic practices (Hao \& Welch, 2012; Hao et al., 2016). Such disadvantages have been exacerbated for female returnees (Leung, 2013; Zweig \& Han, 2010). The lens of diasporic experience in the homeland is appropriate to examine Chinese Ph.D. returnees' relevant experience of entering into the DAJM. In this study, this approach was combined with the ecological environment perspective.

Authors in various disciplines have adopted the ecological environment perspective as a theoretical framework (Neal \& Neal, 2013) so as to study evolving and complex interactions between external environments and human development (Bronfenbrenner, 1977, 1979, 1986a, b). The environment ecology perspective comprises a five-layered system within a nested structure where each layer is inside the next and the focal developing person is at the innermost core (Neal \& Neal, 2013).

The most inner layer includes microsystems in which the focal developing person has direct experience by playing a direct role during interactions with others such as family and friends. Microsystems nest in mesosystems, where two or more microsystems interact, including between the focal person's parents and friends. While the former is a microsystem in relation to a family, the latter is such with regard to a circle of friends. Mesosystems nest in exosystems and refer to formal and informal "social structures," which influence the development of the focal individual who, however, does not constitute a direct part of such social structures (Bronfenbrenner, 1977, p. 515). Macrosystems, where exosystems nest, refer to cultural contexts, for example, ideologies that pattern the interactions in the other three system layers and generate prototypes in a certain society (Bronfenbrenner, 1977, 1979). The chronosystem, as the outer layer (Bronfenbrenner, 1986a, b), emphasizes the "change or continuity [in the environments] across time that influences each of the other systems" (Neal \& Neal, 2013, p. 725). All other fourlayered systems situate in time, which, in turn, can generate changes to them (Bronfenbrenner, 1986b).

Combining the lens of diasporic experience at one's homeland with the ecological environment perspective thus afforded the possibility of exploring the complex situations $\mathrm{Ph}$.D. returnees experience during their entry into the DAJM. Accordingly, an autoethnographic narrative of how various factors in each layer of the environment ecology affected a Chinese female $\mathrm{Ph}$.D. returnee's diasporic experience during her entry into the DAJM is presented in this article.

\section{Methods}

Autoethnography is beneficial to capture "people in the process of figuring out what to do, how to live, and the meaning of their struggles" through personal experience (Bochner \& Ellis, 2006, p. 111). It can identify and interrogate interactions between the inward self and outward social life. This requires rigorous reflexivity (Allbon, 2012). Through autoethnography, one can examine the self in individual narratives (Chang, 2008), thus viewing "individuals within their social environments as actively conferring meaning onto objects in the world, including others and selves" (Bamberg, 2012, p. 79).

In this study, an autoethnographic approach was adopted because it can offer a thick description (Geertz, 1973) of my lived experience of entry into the DAJM. Accordingly, "ground level" (Conquergood, 2002, p. 146) sociological 
evidence is offered to readers to enable them to reconsider the complex life situations of Ph.D. returnees in homelands that are embedded in local cultural and social norms. Furthermore, the risk of blaming the victims when exploring Ph.D. returnees' competitiveness and employability in the DAJM that is embedded in certain academic cultures is questioned.

In relation to the data collection, I did not predesign a project to study myself purposively. Rather, it emerged in conjunction with my job-seeking process when I first realized that I had encountered dilemmas: while my family and friends placed expectational pressures on me, my academic qualifications and productivity were questioned by interviewers. Furthermore, when I sought suggestions related to finding academic jobs from those who had previous experience, I gradually discovered that I was not alone in facing certain challenges. I did not rely on my memory solely to recall the storyline. Rather, my habit of keeping E-diaries in which I narrated my everyday experience ensured ongoing data collection was possible. Based on the snippets recorded in my E-diaries, I was able to discover more related facts, specifically, my perceptions, feelings, and thoughts through my emails, WeChat chatting histories, and WeChat moments. ${ }^{1}$

Because of the COVID-19 pandemic, I returned to China from the United Kingdom on March 15, 2020. Complying with the domestic policy, I spent the first 14 days after returning in my hometown city's quarantine center. I applied for my first job on April 2, 2020 when I was waiting for the online viva voce (viva), which occurred on June 26, 2020. Until October 2020, China implemented strict control measures in relation to mobility restrictions and social distancing. Therefore, I spent almost all my time with my parents at their home. Although intra-city movement has gradually normalized since the middle of October 2020, because the pandemic was well controlled at a domestic level, some super cities in HE, including Beijing, Shanghai, and Guangzhou, suffered an increased number of confirmed cases from November 2020 to January 2021. Consequently, recruiters have been cautious regarding face-to-face interviews. All the interviews I attended were conducted online. The new staff registration of my current post was completed on May 6, 2021. Thus, the story narrated in this article happened between April 2, 2020, and May 6, 2021. In total, 395 E-diaries, 25 emails, WeChat histories with six people, one group chatting history in WeChat, and 10 pieces of WeChat moments relevant to this article were analyzed. Because they

\footnotetext{
$\overline{1}$ WeChat is a Chinese social media, through which people can engage in online chatting by typing words or sending voice messages. WeChat moments are similar to twitter, Instagram and Facebook moments, through which people can share thoughts by typing words and posting photos and short videos.
}

were all written in Chinese, while conducting the analysis, I translated the Chinese into English.

I was both an insider and an outsider during the data analysis. Thus, both empathy and distancing were exercised (Hammersley, 2013) to ensure the presentation of "a rich descriptive story of a particular experience (story text) that pays attention to detail involving all the senses" (Johns, 2010, p. 28). Coffey (1999) asserted that autoethnography is in a danger of self-indulgence. To counteract this, I endeavored to be self-reflexive by developing a clear self-awareness of the researcher-self and the research-self (Coffey, 2004) when I "re-call, re-tell and re-veal" (Allbon, 2012, p. 63) my stories. Although autoethnography is a conversation with self, Sparkes (2013, p. 207) noted that "our stories are not our own" because the involvement of others in our life events is inevitable when we are writing about personal stories (Adams et al., 2015). First, this required me to examine my "thinking, feelings, sense of self and the world" through social interactions with "others" (Adams et al., 2015, p. 47 ), including my family and friends as well as other people involved in my narratives. Moreover, the storyline of this article was communicated with them iteratively during the whole writing process.

Second, it is imperative that I paid special attention to the ethics of this article because of the involvement of other people. I employed the approach of process consent during the data collection and analysis. Process consent acknowledges that written consent is not the only way to obtain consent (Tomaselli et al., 2008). Rather, it regards consent as ongoing that should be both accessible and comfortable for participants. The narratives involved my family, friends, and other crucial individuals during my entry into the DAJM. Before conducting this study, I obtained oral consent from those with whom I was in contact before I decided to conduct the study, during the writing process, and after completing the article. However, with regard to those with whom I have no longer contact such as interviewers, I did not present their direct words and messages, but rather my interpretations, thoughts, and feelings thereof. All those involved have been anonymized to protect their privacy.

\section{Findings}

\section{Expectational Pressures in the Microsystem}

Don't label me! I am not a genius! I am not excellent! I am a normal person! (WeChat moment, 20 December, 2020).

I passed the viva with no corrections. Through WeChat moments, my parents, relatives, and intimate friends expressed their pride and excitement to have such a genius 
as a daughter, sister, niece, and friend. However, the more excited they are, the more I am pressured (Diary, June 26, 2020). I am the only Ph.D. in my family, my circle of friends, and my parents' circle of friends in my hometown. People in the surrounds kept expressing various positive and high expectations about my promising future and privileged status as well as competitiveness in job markets. They believed that I would definitely find a decent job and earn plenty of money. Such expectational pressures kept causing the diasporic feeling I experienced that I did not belong to my family and friends emotionally during my job hunting. This feeling became increasingly overwhelming.

At the outset, most people suggested that I should only apply at Tsinghua or Peking universities. These universities enjoy the highest status in the Chinese HE pyramid in relation to ranking and social reputation. ${ }^{2}$ After I found their recruitment requirements, I tried to explain to those in my surrounds that it is much easier for me to jump into the sky than be accepted by these two universities (Diary, July 18, 2020). My parents and friends tended to encourage me to believe in myself and at least apply for top universities involved in the 985 and 211 projects.

However, this encouragement did not inspire me. Instead, I experienced extreme pressure because they [my parents and friends] will only be disappointed (Diary, August 1, 2020). I tried to explain to them that I did not meet the recruitment requirements in most top universities because I did not have any publications. However, they believed that my competitiveness was associated with the high value of my overseas doctoral degree. I showed them the official statistics on the number of Chinese Ph.D. returnees each year in the hope they would understand how fierce the competition was and thus, lower their expectations. However, they kept encouraging me by impressing upon me how excellent I was.

Being realistic, I did not limit my options to faculty posts only in top universities, but was also willing to receive faculty offers from lower-tier universities or postdoctoral offers. Luckily, I was offered a lecturing post at University J, the so-called ordinary university. I told the people in my surrounds this good news. However, my mother said that she had never heard of it and my uncle tried to persuade me not to accept this offer, but wait for better options (Diary, October 15, 2020). The offer from University J would provide me with bianzhi, which meant it was a permanent post. The first contract period was ten years, during which time I would be unable to change jobs. I would have to pay damages for

\footnotetext{
2 This study does not focus on the rankings of different tiers of Chinese universities. Rather, this study adopts an approximate classification of university rankings and social reputations, which include Tsinghua and Peking Universities at the top, other first-tier universities in Project 211 and Project 985 in the middle, and the others at the bottom.
}

any breach of contract. With this knowledge, my hometown friends suggested that accepting a job at this university was not worth the risk (WeChat chatting, October 16, 2020).

My parents and friends perceived that University J did not suit me because they had never heard of it. On the contrary, their perception that I was excellent matched only Tsinghua and Peking universities. However, if only they knew that I am not that good as they thought. It is so tiring to be so good. I did not want to be good. Couldn't I just have a stable job? (Diary, October 15, 2020).

My wish of if only they knew was a diasporic emotion that was a reflection of the unknown distance between my family and friends and me. It captured the diasporic experience caused by expectational pressures in the microsystem. In other words, although I was near to my family and friends in relation to physical distance, I was not emotionally close to them.

\section{Gender Stereotypes in the Mesosystem}

It is my freedom to choose whether to marry or not! Even at the age of 30! I am an independent female. I don't need a man to buy me a car and house! I can buy them myself! (Diary, July 14, 2020).

I wrote the above extract on my $29^{\text {th }}$ birthday when I held a virtual party via a WeChat group that included my family and friends. In addition to the birthday wishes, in this virtual mesosystem, we spoke about gender stereotypes of a single female Ph.D. who was in her $30^{\text {th }}$ year. My mother endeavored to instill in me that marriage was my current urgency or I would be too old to get married. My uncle assumed that I would definitely become a university teacher whom he believed could enjoy spare time during each summer and winter holiday and thus, be able to care for her children and entire family. My friends believed that I qualified for a husband who had a good financial standing, which could be measured by the number of cars and houses he owned.

A single female with a Ph.D. has a socially constructed identity. First, a female with an overseas Ph.D. degree leads to a good marriage to a man, who can buy her a car and house. Second, a female who works at a university is a good choice for marriage as she will enjoy plenty time to take care of the entire family, especially children during their summer and winter holidays. Finally, a single female at the age of 30 should prioritize getting married and not a professional job. Gender stereotypes within the "affective relations" in the mesosystem exist (Bronfenbrenner, 1979, p. 209). This is where I was embedded during entry into the DAJM, which inevitably resulted in my dilemma of identity negotiation: my self-identity as a professional scholar and the socially constructed identity of a single female at the age of 30 , who should urgently want to become a wife and mother. 
Family members and friends comprise the most intimate social relationships in my life. I cannot ignore what they said like they were strangers. Such gender stereotypes have challenged the values of my doctoral learning experience, the values of my endeavors in job landings and even the values of myself as an independent person (Diary, July 14, 2020)

Countries in East Asia, including China, have a long tradition of patriarchal culture and social norms where females have been positioned in taken-for-granted roles as wives and mothers (Park, 2017), which might limit their perceived possible futures in the professional world (Skilton-Sylvester, 2002). My family and friends perceived it to be abnormal for a female to be single in her thirties. It is normal that a female's competitiveness in the marriage market is demonstrated by the car and house her future husband can buy. Furthermore, it is natural that a female should take her future roles as her husband and children's career into consideration when choosing jobs.

My family and friends perceived two contradicting MEs. One was a Ph.D. returnee, with a promising future in the job market. The other was a single female in her thirties, who encountered the issue of age in the marriage market. On the contrary, her overseas degree itself and expected promising future in the job market could earn her a promising future in the marriage market. Such identity contradictions that existed between the microsystem and mesosystem caused my identity dilemma in relation to who I was. Moreover, the taken-for-granted socially constructed gendered identity in the mesosystem in which I was embedded was in conflict with my own imagination and evaluation of my roles and values in the professional world as an independent person. Such a conflict implies a hidden social border that "crossed" me (Charusheela, 2007, p. 295), thus leading to the diasporic experience of gendered identity negotiation and dilemma.

\section{Guanxi in the Exosystem}

Our guanxi is too distant that they might be useless (Diary, October 2, 2020).

Guanxi refers to the people in my social networks. One of my friends, a Ph.D. returnee from the United States who had experienced entry into the DAJM in 2019 was of the opinion that some interviewers made a decision before the interview in accordance with the internal recommendations of high-profile people. This demonstrates the crucial role of unique and informal "social structures" in exosystems (Bronfenbrenner, 1977, p. 515), guanxi in the acquisition of academic posts in China. When I realized this, I began to brainstorm all domestic academic contacts I have had.

Friends of mine in Chinese universities were not high profiles in relation to making recruitment decisions. I had also built social networks through international conferences and seminars with people who were associate professors and professors in Chinese universities. Although I was not sure whether they were willing to help, I messaged Sophia, an associate professor in University $\mathrm{T}$, through WeChat after I had seen a postdoctoral recruitment from the university in which I was interested. Sophia passed my academic CV and other relevant materials to the project investigator. Three hours later, I received an email from the project investigator's secretary in relation to online interview information. I was made an offer at the site. The project investigator finally communicated the advantages his team enjoyed in relation to academic networks, which he expected me to make the most of. Although I did not accept this offer initially, the power of guanxi surprised me eventually (Diary, October 7, 2020).

First, the data in this section concur with previous studies in which the significant roles of guanxi in the Chinese job market (Bian, 1994) and the issue of deep-rootedness in Chinese academic job markets (Jiang et al., 2020) have been revealed. Second, the data demonstrated "diasporic as type of consciousness" (Vertovec, 1997, p. 281). After obtaining a bachelor's degree, I taught English in my hometown for four years. Before I went to the United Kingdom to pursue my Ph.D. in education, I did not officially have a master's degree from a Chinese university. This means that I had no root in relation to academic links with Chinese academia in the field of education. Being fully aware of my disadvantages, I actively attended academic conferences and seminars so as to present my $\mathrm{Ph}$.D. research to Chinese scholars and those interested in Chinese educational studies. When I recollected my experience of entry into the DAJM reflectively, I realized that my self-consciousness of my disadvantages in relation to my rootless status in Chinese academia illustrates the diasporic consciousness I had already developed in my mind. This diasporic consciousness had urged me to tell Sophia about my research and myself on certain academic occasions previously, which, in the context of this study, advantaged me in relation to guanxi in the exosystem during my entry into the DAJM.

\section{Academic Culture in the Macrosystem}

While recalling the entire job-seeking experience, certain consistencies in the macrosystem (Bronfenbrenner, 1977, 1979) related to the Chinese academic culture in job markets emerged, including bias associated with the origin of one's degree and prioritizing publications.

My pathway to be awarded a Ph.D. without a master's degree was questioned constantly by interviewers. My explanation always involved an archeology of my experience. I wanted to convince the interviewers that although I did not follow a traditional academic course, I was not disadvantaged. In addition, I possessed more first-hand working 
experience than students with master's degrees. My working experience facilitated my doctoral research. Although some interviewers expressed their appreciation, I was finally notified that I did not meet their criteria. I did not have a clear understanding of the criteria until my interview with the school of education at University $\mathrm{Z}$. The dean of the school explained sincerely that even if they could make me an offer, the screening at university level would disqualify me. My story would not be heard, but only the facts written on paper would be seen. First, I did not obtain my bachelor's degree from a prestigious university such as University Z. Second, I did not have a master's degree (Diary, December 23, 2020).

I obtained my bachelor's degree from University N, which is part of the 211 Project but not the 985 Project. University $\mathrm{Z}$ is part of both projects and thus, enjoys higher status in relation to ranking and social reputation in comparison to University $\mathrm{N}$. The data in this study revealed two dimensional consistencies that are prevalent in the Chinese academic recruitment culture. First, authorities at school or department level cannot make personnel decisions, even if they conduct face-to-face interviews with candidates. Rather, university level authorities finalize the name list in accordance with what was written on the application forms. Second, the origin of candidates' degree has an considerable effect on their entry into Chinese academic job markets, especially when they apply at more prestigious universities than from where they originally graduated.

In addition to degree origin bias, pre-employment publication records are also an influential aspect in Chinese academic culture (Jiang et al., 2020). I was interviewed twice in early May 2020, approximately one and half months before the viva. The interviewers at both universities expressed their doubts as to whether I had been awarded a Ph.D. degree because at the time, I had no publications (Diary, May 6, 2020; May 10, 2020). I explained that publications are not a compulsory criterion to be awarded a Ph.D. degree in the United Kingdom, which is different in China. When the interviewers at University $\mathrm{M}$ found out that I had a journal article under review, they suggested that they would reconsider my application once the article was published (Diary, May 10, 2020). I had a similar experience during interviews at four other universities (Email, June 8, 2002; June 16, 2020; October 8, 2020; November 17, 2020). On November 18,2020 , I received an acceptance letter for my article. I immediately updated my $\mathrm{CV}$, contacted certain universities again, initiated a new round of applications for some prestigious universities, which I had been not qualified for in terms of publications (Diary, November 19, 2020).

The situation became better with one accepted article to certify myself (WeChat moment, December 1, 2020). I was invited to interviews by two well-renowned universities for postdoctoral posts (University B and T). Three universities, which I had re-contacted, agreed I could hand in my materials to be considered for lecturer posts (University K, L, and H). Finally, I received postdoctoral offers from University B and T. However, I only qualified for the lowest level of research facilities, stipend, and other livelihood necessities. The human resource (HR) staff at both universities notified me that salary and other material benefits for academic staff depended on research productivity, which, according to the universities' regulations, were measured primarily by one's number of published articles (Diary, January 8,2021 ).

Universities $\mathrm{K}, \mathrm{L}$, and $\mathrm{H}$ asked me about my willingness to start with a two-year postdoctoral post, after which there would be a greater possibility of obtaining a permanent post once I had enough articles published in high-impact journals (Diary, January 15, 2021). These universities' regulations on academic promotion explain what is meant by enough. Universities $\mathrm{K}$ and $\mathrm{H}$ required three first-authored articles published in high-impact journals with the universities as the affiliation will be eligible to compete for the posts of assistant professor (Diary, January 6, 2021). University $\mathrm{L}$ required key performance indicators of postdoctoral contracts to determine the postdoctoral researchers that would be given preferential considerations for faculty posts (Diary, January 10, 2021). Once it was known that I had one accepted journal article and another two under review, three universities requested that I change my affiliation on the article to them (Diary, December 10, 2020; December 17, 2020; December 27, 2020).

Exclusion and displacement in the mainstream societies of either host countries or homelands have been associated with studies on diasporic experience (Grossman, 2018; Xu, 2019). My experience related to the Chinese academic culture of publish or perish generated my diasporic feeling of being exiled in the DAJM, where I doubted my initial purpose of pursuing a doctoral degree (Diary, December 10, 2020), which was to resolve my questions that had emerged during my previous working experience. However, this purpose did not appear to be valued in the DAJM.

\section{COVID-19 in the Chronosystem}

In relation to the definition of the chronosystem, which was noted previously, it may be argued that the COVID-19 pandemic is an unexpected and non-normative change in the external environment in which the focal developing person is living and the other four systems are influenced (Bronfenbrenner, 1986a, b). First, the COVID-19 pandemic has constrained people's physical movements, including those of my parents and me. Thus, I spent all my time at home, thus leading to more face-to-face interactions with my parents who had more opportunities to express their expectations about my promising future from time to time in the microsystem. Although they did not intend to make me feel 
stressed, such expectational pressures led to my diasporic experience of being away from my family and friends emotionally during my job-seeking journey. Second, because of mobility restrictions owing to the COVID-19 pandemic, face-to-face interviews had to be conducted on online platforms. Furthermore, it changed human interactions in the other four systems. It was very difficult to fully express my passion and enthusiasm to them [interviewers] (Diary, September 25, 2020). Two interviews were interrupted because of poor internet connections, which made me more anxious and I didn't think I conducted myself well (Diary, September 10, 2020; October 19, 2020). Two arranged face-to-face interviews in Beijing in November 2020 and January 2021, one in Shanghai in December 2020, and one in Guangzhou in November 2020 were canceled at short notice. They have not yet been rescheduled. In addition, a significant number of Chinese students who were overseas chose to leave their host countries and return home (Mok, 2020). Approximately $90 \%$ of Chinese students who were studying in British universities left the United Kingdom by the middle of 2020 (Stevenson \& May, 2020). This potentially increased intracompetition among Ph.D. returnees in the DAJM. After knowing that I had accepted a postdoctoral offer, Jenny, a university recruiter with whom I kept contact via WeChat, told me that they had received many more applications from $\mathrm{Ph} . \mathrm{D}$. returnees than previous years and suggested I acquire domestic experience and gain access to social networks to ensure my competitiveness for faculty posts.

Even after accepting my current postdoctoral offer, the challenges caused by the COVID-19 pandemic remained considerable. The prolonged administrative process, for example, lasted from the middle of January 2020 until the end of April 2021. The HR personnel explained to me had it not been for the pandemic, the registration process would have been completed within one month (Diary, April 15, 2021). However, a diasporic experience of being displaced inevitably caused me to feel uncertain. Did they really decide to give me this offer? Will anything happen? (Diary, March 30, 2021). Although I was hesitant that maybe I should continue to apply for other posts (Diary, March 30, 2021), eventually I did not apply because the whole process really makes me exhausted (WeChat moment, April 4, 2021) and this postdoctoral project really fits my plan quite well (Diary, April 15, 2021). However, the prolonged administrative process caused by COVID-19 caused anxieties, pressure, and even traumatic feelings. Being an adult with no stable income (Diary, April 15, 2021), I was in a diasporic mindset in which I purposely distanced myself from local communities as I was afraid of answering questions related to my promising future, which people in my surrounds assumed I had. I became a self-constructed diaspora at home in the chronosystem during my job-seeking journey into the DAJM. Eventually, I started to earn a salary on May 6, 2021.

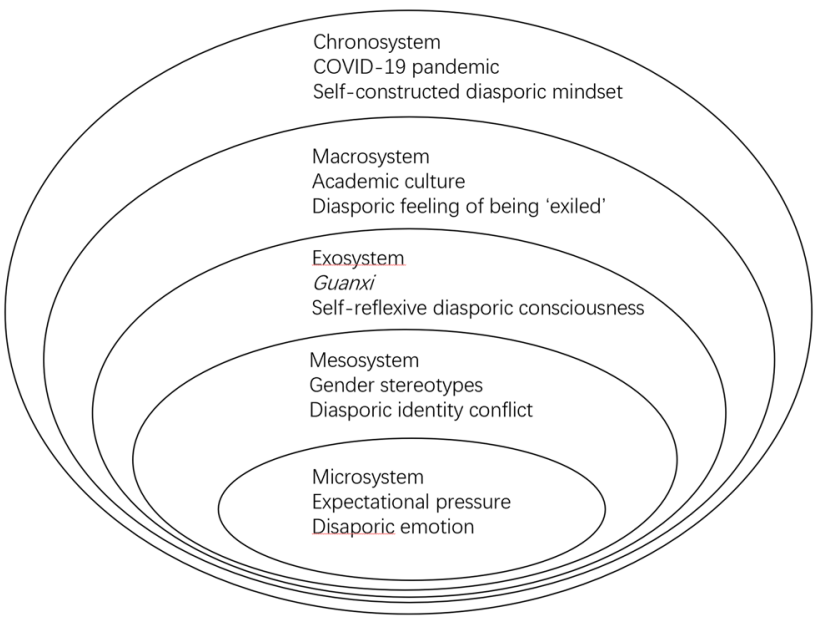

Fig. 1 Diasporic experience in the five-layered environment ecology perspective

When I breathed deeply, settled my mind, and began to recollect the whole story at midnight on May 6, 2021, a whole calendar year plus one month and four days had passed since my first job application. A vivid picture of my diasporic experience during this journey, which was embedded in the five-layered environment ecology perspective, came to my mind. This is depicted in Fig. 1.

\section{Discussions and conclusion}

This study comprises an autoethnographic narrative in which the influences of various factors in the five-layered environment ecology perspective on a Chinese female $\mathrm{Ph}$.D. returnee's diasporic experience of entering into the DAJM are discussed. Such a diasporic experience comprises diasporic emotion caused by expectational pressures in the microsystem, diasporic identity conflict that originates from gender stereotypes in the mesosystem, self-reflexive diasporic consciousness of both disadvantages and advantages from guanxi in the exosystem, the diasporic feeling of being exiled in the DAJM given the academic culture in relation to degree origin bias and publication priority in the macrosystem, and the self-constructed diasporic mindset in which uncertainties and anxieties associated with the unexpected and non-normative COVID-19 pandemic in the chronosystem are experienced. Such diasporic experience revealed various challenges posed by factors in the external environment that were out of control and subsequently intensified during the COVID-19 pandemic. Such challenges are similar to mobility friction (Lorimar-Leonard, 2017), stemming from conflicts among personal values and social norms, personal values, and the academic culture in China in the context of this study. Such conflicts made it difficult 
to mobilize my knowledge, passion, and whatever resources I owned so as to navigate my entry into the DAJM.

Autoethnography has limitations, especially in relation to the emphasis on personal feelings, thoughts, and impressions (Winkler, 2018), which may have limited the analytical scope of this study such as the potentially differentiated experience based on Ph.D. returnees' funding status and disciplines. It is recommended that further studies be conducted on this. Different readers may interpret the story presented in this article differently and thus, have varied reflections. I am of the view this article has two implications of which readers are invited to judge the plausibility in accordance with their own specific experiences.

First, the ecological environment perspective that was employed to explore the diasporic experience requires a shift from the risk of blaming the victims when examining $\mathrm{Ph}$.D. returnees' competitiveness and employability in the DAJM through hard indicators. The theoretical approach employed in this study facilitates a sociological exposition and understanding of the complex situation of Ph.D. returnees' experience of entry into the DAJM. Studies have revealed that Chinese overseas degree holders usually have higher expectations concerning their status in domestic labor markets (Hao et al., 2016) and demonstrate genderrelated bias in academic job markets from the employers' perspectives in relation to screening and promotion criteria (Caprile et al., 2011; Shen et al., 2018; Silander et al., 2021). The data in this study revealed how expectational pressures from family and friends in the microsystem and the socially constructed gendered identity in the mesosystem generated a Ph.D. returnee's diasporic emotion and identity conflict. Having high expectations toward children's education has been regarded as one of the educational values in Chinese traditional culture that has a considerable influence on Chinese parents' educational practices in contemporary society (Xu \& Montgomery, 2021). However, this has not been explored much in the context of Ph.D. returnees' entry into the DAJM. This study contributes to the sociological reflections on the social norms related to the taken-for-granted promising status of $\mathrm{Ph}$.D. returnees and socially constructed gendered identity of female Ph.Ds. Such reflections are believed to be transferable to countries, especially those in the global south that have experienced an exit of students seeking doctoral degrees in global north countries as well as those with patriarchal culture traditions such as in East Asia.

Second, the findings of this article contribute empirically to discussions on the challenges faced by Ph.D. returnees' entry into the DAJM, which is embedded in the academic culture of deep-rootedness as well as recruitment practices of degree origin bias and publish or perish. The implications of this study are not limited to questioning the academic norms in the Chinese academic job market. Rather, it can be extended to the global sphere because the considerable emphasis on publications and deep-rootedness in academic job markets tend to be global issues (Delicado, 2011; Pham, 2020). It is recommended that a comparative study of the experience of Ph.D. returnees' entry into the DAJM in international contexts be conducted.

It is also hoped that this study will inform future overseas doctoral students and Ph.D. returnees with first-hand stories so that they can acquire a more practical sense of the potential frictions embedded in transnational education mobility related to job seeking in homelands. I would like my story to generate their reflections on how to navigate the potential frictions that originate from the values paradox. Furthermore, it is hoped that my voice will be heard by Chinese educational practitioners with regard to reforming recruiting practices and educational evaluation to develop an inclusive and diverse HE environment to facilitate returnees' navigations, especially those who want to pursue a career in research.

\section{References}

Adams, T. E., Holman Jones, S., \& Ellis, C. (2015). Autoethnography. Oxford University Press.

Allbon, C. (2012). "Down the rabbit hole-curiouser and curiouser": Using autoethnography as a mode of writing to re-call, re-tell and re-veal bodily embodiment as self-reflexive inquiry. Journal of Organizational Ethnography, 1(1), 62-71.

Bamberg, M. (2012). Narrative analysis. In H. Cooper (Ed.), APA handbook of research methods in psychology (pp. 77-94). American Psychological Association.

Band, A. (1996). The new diasporism and the old diaspora. Israel Studies, 1(1), 323-331.

Bian, Y. J. (1994). Guanxi and the allocation of jobs in urban China. The China Quarterly, 140, 971-999.

Bochner, A. P., \& Ellis, C. S. (2006). Communication as autoethnography. In G. J. Shepherd, J. St. John, \& T. Striphas (Eds.), Communication as...: Perspectives on Theory (pp. 110-122). Thousand Oaks, CA: SAGE.

Bronfenbrenner, U. (1977). Toward an experimental ecology of human development. American Psychologist, 32, 513-531.

Bronfenbrenner, U. (1979). The ecology of human development: Experiments by nature and design. Harvard University Press.

Bronfenbrenner, U. (1986a). Recent advances in research on the ecology of human development. In R. K. Silbereisen, K. Eyferth, \& G. Rudinger (Eds.), Development as action in context: Problem behavior and normal youth development (pp. 287-309). Springer.

Bronfenbrenner, U. (1986b). Ecology of the family as a context for human development: Research perspectives. Developmental Psychology, 22, 723-742.

Brubaker, R. (2005). The "diaspora" diaspora. Ethnic and Racial Studies, 28(1), 1-19.

Burris, V. (2004). The academic caste system: Prestige hierarchies in Ph.D. exchange networks. American Sociological Review, 69(2), 239-264.

Campt, T., \& Thomas, D. (2008). Editorial: Gendering diaspora: Transnational feminism, diaspora and its hegemonies. Feminist Review, 90, 1-8. 
Caprile, M., Meulders, D., O’Dorchai, S. P., \& Vallès, N. (2011). Introduction to the special issue Gender and science: Old challenges, new approaches. Brussels Economic Review, 54(2-3), $108-129$.

Chang, E. (2008). Autoethnography as method. Left Coast Press.

Charusheela, S. (2007). The diaspora at home. Cultural Dynamics, 19(2/3), 279-299.

Chen, H. (2005). Reviewing "Hai Gui" and "Hai Dai." In X. Zhu (Ed.), Zhongguo jiaoyu redianwentitoushi (Scaning Chinese education issues) (pp. 14-17). Anhui Jiaoyu Chubanshe (Anhui Education Publisher).

Chen, Q. (2017). Globalization and transnational academic mobility: The experiences of Chinese academic returnees. Springer.

China Statistical Yearbook. (2020). [in Chinese] http://www.stats.gov. $\mathrm{cn} / \mathrm{tj} \mathrm{sj} / \mathrm{ndsj} / 2020 / \mathrm{indexch} . \mathrm{htm}$

Coffey, A. (1999). The ethnographic self. SAGE.

Coffey, A. (2004). Autobiography. In M. L. Beck, A. Bryman, \& T. F. Liao (Eds.), The Sage encyclopaedia of social science research methods (pp. 45-46). Sage Publications.

Conquergood, D. (2002). Interventions and radical research. The Drama Review, 46(2), T1-74.

Conti, A., \& Visentin, F. A. (2015). Revealed preference analysis of $\mathrm{PhD}$ students' choices over employment outcomes. Research Policy, 44(10), 1931-1947.

DDG/P Office and OECD. (2020). The impact of the COVID-19 pandemic on jobs and incomes in G20 economies https://www.ilo. org/global/about-the-ilo/how-the-ilo-works/multilateral-system/ g20/reports/WCMS_756331/lang--en/index.htm.

Delicado, A. (2011). The consequences of mobility: Careers and work practices of Portuguese researchers with a foreign $\mathrm{PhD}$ degree'. In F. Dervin (Ed.), Analysing the Consequences of International Academic Mobility (pp. 163-180). Newcastle: Cambridge Scholars Publishing.

European University Institute (2021). Academic careers observatory: Impact of Covid-19 on the academic job market in the social sciences and the humanities. Accessed Apr 2021.

Geertz, C. (1973). The interpretation of cultures: Selected essays. Basic Books.

Gerhards, J., Silke, H., \& Carlson, S. (2017). Social class and transnational human capital: How middle and upper class parents prepare their children for globalization. Routledge.

Gould, J. (2020). The career costs of COVID-19: How postdocs and $\mathrm{PhD}$ students are paying the price https://www.nature.com/artic les/d41586-020-03108-4https://www.eui.e.u/ProgrammesAndFe llowships/AcademicCareersObservatory.

Grossman, J. (2019). Toward a definition of diaspora. Ethnic and Racial Studies, 42(8), 1263-1282.

Gu, J., Levin, J. S., \& Luo, Y. (2018). Reproducing "academic successors" or cultivating "versatile experts": Influences of doctoral training on career expectations of Chinese $\mathrm{PhD}$ students. Higher Education, 76(3), 427-447.

Hammersley, M. (2013). What is qualitative research? Bloomsbury Academic.

Hao, J., \& Welch, A. (2012). A tale of sea turtles: Job-seeking experiences of hai gui (high-skilled returnees) in China. Higher Education Policy, 25(2), 243-260.

Hao, J., Wen, W., \& Welch, A. (2016). When sojourners return: Employment opportunities and challenges facing high-skilled Chinese returnees. Asian and Pacifc Migration Journal, 25(1), 22-40. https://doi.org/10.1177/0117196815621806

$\mathrm{Hu}, \mathrm{D}$. (2021). Understanding transnational academic migration: US doctorate recipients' choices of returning to Chinese academe. International Journal for Educational and Vocational Guidance, 21, 1-17. https://doi.org/10.1007/s10775-021-09459-2

Huang, F., \& Shen, W. (2019). What determinants affect doctoral students' career plans? Main findings from a 2018 survey of Chinese doctoral students. International Journal of Chinese Education, 8(2), 99-116.

Headworth, S., \& Freese, J. (2016). Credential privilege or cumulative advantage? Prestige, productivity, and placement in the academic sociology job market. Social Forces, 94(3), 1257-1282.

Jiang, J., Mok, K. H., \& Shen, W. (2020). Riding over the national and global disequilibria: International learning and academic career development of Chinese Ph.D. Returnees. Higher Education Policy. https://doi.org/10.1057/s41307-019-00175-9

Jiang, J., \& Shen, W. (2019). International mentorship and research collaboration: Evidence from European-trained Chinese Ph.D. returnees. Frontiers of Education in China, 14(2), 180-205.

Johns, C. (Ed.). (2010). Guided reflection: A narrative approach to advancing professional practice. Wiley-Blackwell.

Jung, J. (2018). Domestic and overseas doctorates and their academic entry-level jobs in South Korea. Asian Education and Development Studies, 7(2), 205-222.

Kellogg, R. P. (2012). China's brain gain: Attitudes and future plans of overseas Chinese students in the US. Journal of Chinese Overseas, 8(1), 83-104. https://doi.org/10.1163/179325412X634319

Kim, J. (2016). Global cultural capital and global positional competition: International graduate students' transnational occupational trajectories. British Journal of Sociology of Education, 37(1), $30-50$.

Kwak, D., \& Song, J. (2015). Literature examined under the diasporic Lens: Emotional diaspora present in madame butterfly. Journal of Arts and Humanities, 4(8), 18-24.

Lee, J. J., \& Kim, D. (2010). Brain gain or brain circulation? US doctoral recipients returning to South Korea. Higher Education, 59(5), 627-643.

Leung, M. W. H. (2013). Unraveling the skilled mobility for sustainable development mantra: An analysis of ChinaEU academic mobility. Sustainability (switzerland), 5(6), 2644-2663. https://doi.org/10. $3390 /$ su5062644

Li, J., \& Xue, E. (2020). Returnee faculty responses to internationalizing "academic ecology" for creating world-class universities in China's elite universities. Higher Education, 81, 1063-1078.

Lin, P. (2011). Chinese diaspora" at home": Mainlander Taiwanese in Dongguan and Shanghai. China Review, 11(2), 43-64.

Liu, G. (2019). Research on guiding overseas teachers to participate in the internationalization construction of colleges. Education and Teaching Forum, 22(02), 192-193.

Lorimer-Leonard, R. (2017). Writing on the move: Migrant women and the value of literacy. University of Pittsburgh Press.

Ministry of Human Resources and Social Security. (2019). The statistics on the national human resource in $2019 \mathrm{http}: / / \mathrm{www} . \mathrm{mohrss}$. gov.cn/SYrlzyhshbzb/zwgk/szrs/tjgb/202006/W02020060853464 7988832.pdf.

Ministry of Education. (2019). The statistics on the overseas students in 2019. [In Chinese] http://www.moe.g.ov.cn/jyb_xwfb/gzdt_gzdt/ s5987/202012/t20201214_505447.html.

Mok, K. H. (2020). Will Chinese students want to study abroad postCOVID-19. University World News, July 4. https://www.unive rsityworldnews.com/post.php?story $=20200703155021111$.

Neal, J. W., \& Neal, Z. P. (2013). Nested or networked? Future directions for ecological systems theory. Social Development, 22(4), $722-737$.

Park, G. (2017). Narratives of East Asian women teachers of English: Where privilege meets marginalization. Multilingual Matters.

Pham, T. (2020). Reconceptualizing employability of returnees: What really matters and strategic navigating approaches. Higher Education, 81, 1329-1345.

Powell, K. (2015). The future of the postdoc. Nature, 520(7546), 144.

Rizvi, F. (2000). International education and the production of global imagination. In N. Burbules \& C. Torres (Eds.), Globalisation and education: Critical perspectives (pp. 205-225). Routledge. 
Shen, W., Gao, Y., Zhang, B., \& Jiang, J. (2018). Academia or enterprises: Gender, research outputs, and employment among $\mathrm{PhD}$ graduates in China. Asia Pacific Educ. Rev., 19, 285-296. https:// doi.org/10.1007/s12564-018-9538-5

Skilton-Sylvester, E. (2002). Should I stay or should I go? Investigating Cambodian women's participation and investment in adult ESL programs. Adult Education Quarterly, 53(1), 9-26.

Silander, C., Haake, U., Lindberg, L., \& Riis, U. (2021). Nordic research on gender equality in academic careers: A literature review. European Journal of Higher Education. https://doi.org/ 10.1080/21568235.2021.1895858

Shen, W., \& Wang, C. (2018). Historical trends in Ph.D. study abroad and their implications for transforming the Chinese higher education system. In P. A. Oleksiyenko, Q. Zha, I. Chirikov, \& J. Li (Eds.), International status anxiety and higher education: soviet legacies in China and Russia (pp. 309-334). Hong Kong: Comparative Education Research Centre and Springer.

Sparkes, A. C. (2013). Autoethnography at the will of the body: Reflections on a failure to produce on time. In N. P. Short, L. Turner, \& A. Grant (Eds.), Contemporary British autoethnography (pp. 203-211). Sense Publishers.

Stevenson, A., \& Tiffany M. (2020). Coronavirus Strands China's Students, in a Dilemma for Beijing. June 6. https://www.nytim es.com/2020/04/05/world/asia/coronavirus-china-students.html.

Tharenou, P., \& Seet, P.-S. (2014). China's reverse brain drain: Regaining and retaining talent. International Studies of Management \& Organization, 44(2), 55-74. https://doi.org/10.2753/IMO00208825440203

Tomaselli, K. G., Dyll, L., \& Francis, M. (2008). Self and “other.” In N. K. Denzin, Y. S. Lincoln, \& L. T. Smith (Eds.), Handbook of critical and indigenous methodologies (pp. 347-372). Sage.

UIS.UNESCO. (2021). http://uis.unesco.org/en/uis-student-flow.

Vertovec, S. (1997). Three meanings of "diaspora", exemplified among South Asian religions. Diaspora, 6(3), 277-299.

Winkler, I. (2018). Doing autoethnography: Facing challenges, taking choices, accepting responsibilities. Qualitative Inquiry, 24(4), 236-247.
Woolley, R., Turpin, T., Marceau, J., \& Hill, S. (2008). Mobility matters: Research training and network building in science. Comparative Technology Transfer and Society, 6(3), 159-184.

Xu, C. L. (2019). 'Diaspora at home': Class and politics in the navigation of Hong Kong students in Mainland China's Universities. International Studies in Sociology of Education. https://doi.org/ 10.1080/09620214.2019.1700821

Xu, X., Rose, H., \& Oancea, A. (2021). Incentivizing international publications: Institutional policymaking in Chinese higher education. Studies in Higher Education, 46(6), 1132-1145.

$\mathrm{Xu}, \mathrm{X} .$, Sit, H. H. W., \& Chen, S. (2020). The Eastern train on the Western track: An Australian case of Chinese Doctoral students' adaptation. Singapore: Springer Singapore.

Xu, Y. R., \& Montgomery, C. (2021). Understanding the complexity of Chinese rural parents' roles in their children's access to elite universities. British Journal of Sociology of Education, 42(4), 555-570.

Yang, L., \& Marini, G. (2019). Research productivity of Chinese young thousand talents. International Higher Education, 97, 17-18.

Yang, X., \& You, Y. (2018). How the world-class university project affects scientific productivity? Evidence from a survey of faculty members in China. Higher Education Policy, 31(4), 583-605.

Zweig, D. (2006). Competing for talent: China's strategies to reverse the brain drain. International Labour Review, 145, 65-90.

Zweig, D., Changgui, C., \& Rosen, S. (2004). Globalization and transnational human capital: Overseas and returnee scholars to China. The China Quarterly, 179, 735-757.

Zweig, D., \& Han, D. (2010). Images of the world: Studying abroad and Chinese attitudes towards international affairs. The China Quarterly, 202, 290-306.

Publisher's Note Springer Nature remains neutral with regard to jurisdictional claims in published maps and institutional affiliations. 